\title{
Subsídios para mudanças do modelo de assistência psiquiátrica
}

\author{
Elements for changing a prevailing psychiatric \\ care model
}

Fernando Ferreira Pinto de Freitas 1

1 Departamento de Ensino
de Graduação,
Universidade do Estado
do Rio de Janeiro.
Rua São Francisco Xavier 524,
Rio deJaneiro, RJ
20559-900, Brasil.
ffreitas@uerj.br
Abstract This study presents the results of research done at the Pedro II Psychiatric Center in 1995, as part of a partnership between the Center and the Universi dade do Estado do Rio de Janeiro. Research includes the devel opment of a profile for inpatients based on clinical and soci oeconomic data from patient files, emergency ward assessment of the group's interactive abiliti es based on WHO parameters, and a critical analysi s of the psychiatric care model employed in the Psychiatric Center. With the psychiatric reform pursued by major sectors of Brazilian soci ety, we intend not only to respond to the economic/admi nistrative irrational ity created by "hospitalcentrism", but especially to meet the needs of patients, health professionals, and society in general in moving away from a psychiatric care model dominated by the reference patterns of psychiatry and to de-institutional ize mental health. The results of this study criticize the bi omedical model and open the door to a care model engaged in "psychosocial rehabilitation". The critical anal ysi s based upon the data from the investigation done at the Psychiatric Center should beapplicable to other psychiatric hospitals in Brazil's public and private sectors.

Key words Psychiatry; Deinstitutionalization; Community Psychiatry; Mental Health

Resumo Este trabalho apresenta os resultados da investigação realizada no Centro Psi quiátrico Pedro II (CPPII), durante o ano de 1995, como parte do convênio Uerj/CPPII. A investigação engloba uma construção do perfil da clientela hospitalizada, segundo os dados clínicos e sócioeconômi cos que constam nos prontuários; uma aval iação das capaci dades interativas da clientela no Pronto-Socorro Psi quiátrico, de acordo com critérios recomendados pela OMS; e, finalmente, uma análise crítica do modelo de assi stência em uso no CPPII. Com a reforma psiquiátrica que vem sendo objeto de luta de significativos setores da nossa sociedade, pretende-se não apenas responder à irracionali dade econômi co-administrativa gerada pel o 'hospital ocentrismo', mas, sobretudo, atender às necessi dades da cl ientela, dos profissi onais de saúdee da soci edade em geral. Tais necessi dades equi valem substancial mente a desinstitucionalizar a saúde mental do modelo de assistência dominado por quadros de referência da psiquiatria. Os resultados da investigação aqui descritos e explicados criticam os indicadores construídos segundo o model o de cura e abrem perspecti vas para um modelo de assistência comprometi do com a reabi litação psicossocial da clientela. A análise crítica efetuada com base nos dados da investi gação feita no CPPII é mui to provavel mente extensi va aos outros hospitais psi quiátricos da nossa rede pública eprivada.

Palavras-chave Psiquiatria; Desinstitucionalização; Psi quiatria Comunitária; Saúde Mental 


\section{Considerações preliminares}

\section{O ponto de partida}

A presente investigação trabalha com um dos centros de interesse da reforma psiquiátrica no Brasil: a qualidade dos indicadores empregados. Trata-se de um dos aspectos críticos da reforma, porque os indicadores expressam o modo como a instituição psiquiátrica constrói o seu objeto de intervenção. Quem é a sua clientela? Qual é a demanda? Como são planejadas as prestações de serviço? Com que finalidades? Como se avalia o que é feito?

Algumas idéias diretrizes orientaram a perspectiva dos investigadores. Uma delas é quea reforma do nosso sistema de assistência em saúde mental está sendo implementada com um significativo atraso histórico. Visa-se adequar o nosso sistema de assistência à tendência universal de superação do 'hospitalocentrismo', por meio da construção de uma rede de serviços de natureza comunitária e compreensiva. Há décadas, as chamadas sociedades de capitalismo avançado, ou pós-industriais já se deram conta da irracionalidade econômico-administrativa de organizar o sistema de assistência psiquiátrica segundo os parâmetros tirânicos impostos pelo hospital psiquiátrico, bem como dos imperativos éticos e terapêuticos de superação do paradigma de cura que caracteriza a medicina mental. O papel do hospital psiquiátrico permanece hegemônico no sistema psiquiátrico brasileiro. Conseqüentemente, são escassos os serviços que promovem a reabilitação psicossocial da clientela, na maioria das vezes restritos ao âmbito do hospital psiquiátrico. Não é por acaso que em nossa literatura pouco se discute sobre os indicadores que enfocam a clientela segundo os quadros de referência que garantem a desinstitucionalização da doença mental.

Uma segunda idéia diretriz é que o papel representado pela instituição investigada para a assistência pública no Rio de Janeiro, isto é o Centro Psiquiátrico Pedro II (CPPII), não difere substancialmente do quadro geral da assistência psiquiátrica no País. Trata-se de um grande complexo de unidades hospitalares, com a responsabilidade de prestar assistência para mais de dois milhões de pessoas. Conta com um Pronto-Socorro Psiquiátrico como porta de entrada para o sistema, com dois componentes organizacionais, a Enfermaria de Emergência e a Enfermaria de Acolhimento da Crise. Oferecem-se prestações de serviço ambulatorial de segunda a sexta-feira. E, para a população com hospitalização de médio ou longo prazo, há três unidades com um total de cerca de trezentos internos. É bem verdade que importantes iniciativas vêm sendo implementadas nas últimas décadas. Várias unidades foram desativadas ou reconvertidas para finalidades que não são aquelas do modelo asilar, como é a Casa do Engenho, estruturada para ser um ‘hospitaldia', ou o Centro Comunitário, um antigo paviIhão asilar, que abriga um conjunto de entidades da soci edade civil organizada; há ainda as pensões protegidas, ou então a Escola Municipal que atende as crianças da comunidade. Apesar dessas e outras iniciativas, à medida em que elas se reproduzem nos 'quadros de experiência' hospitalares, a clientela permanece sendo assistida segundo os indicadores da medicina mental.

A terceira idéia diretriz é que quem recebe e se relaciona com a clientela não é a história da instituição, mas seus atores institucionais, segundo uma determinada atenção organizada. É por isso que decidimos reconstruir a relação instituição/ clientela, tomando como referência os indicadores que constam dos prontuários, ignorando propositadamente eventuais artigos sobre o CPPII.

Finalmente, a equipe de investigadores trabalhou com a idéia de que é na porta de entrada que a história da clientela na instituição é definida, na maioria dos casos. Tomou-se como amostra um conjunto de pacientes que ingressaram na instituição pelo Pronto-Socorro Psiquiátrico e acompanhou-se a sua trajetória tendo por base os dados dos seus prontuários.

\section{Objetivos}

a) Descrever a clientela hospitalizada no CPPII, segundo os indicadores utilizados pela instituição.

b) Descrever e avaliar as demandas da clientela, segundo indicadores alternativos próprios da reabilitação psicossocial.

\section{Determinação das amostras}

a) Para traçar o perfil da clientela segundo os parâmetros vigentes na instituição, foi tomado como referência o movimento total dos atendimentos no seu pronto-socorro. O período foi o ano de 1994. Do total de 12.600 casos registrados nesse período como internados, foi retirada uma amostra de cem pacientes, selecionados de forma aleatória entre os indivíduos agrupados proporcionalmente conforme o diagnóstico dado no pronto-socorro. 
b) Para descrever e avaliar as capacidades interativas da clientela, a equipe entrevistou uma outra amostra de 21 casos, igualmente de indivíduos ingressos via pronto-socorro, durante um período de dois meses em 1995.

\section{Desenho dos instrumentos}

a) Para traçar o perfil da clientela segundo os parâmetros vigentes na instituição, utilizaramse os prontuários como instrumento. É de se esperar que estejam registrados em cada prontuário todos os dados considerados relevantes sobre o paciente e a sua história de vida, sobre as circunstâncias imediatas da sua crise, o diagnóstico e o prognóstico construído, os procedimentos terapêuticos adotados e, finalmente, os dados sobre a recuperação do paciente.

b) Para a amostra da clientela, analisada segundo os critérios alternativos da reabilitação psicossocial, utilizou-se a escala OMS/DAS. Tal escala, elaborada para a avaliação de incapacidade psiquiátrica, é composta por um questionário semi-estruturado, abordando o que é normativamente esperado do comportamento de todo e qualquer indivíduo do mesmo sexo, idade e ambiente sócio-cultural. Brevemente, com a escala, são avaliados o comportamento global eo desempenho de papéis sociais. As informações sobre a conduta do paciente no último mês que antecede à crise identificada pela instituição devem ser obtidas de um informante-chave, confirmadas pelo paciente. A enfermagem também deve ser entrevistada sobre o comportamento do indivíduo durante o período de hospitalização. As respostas são cotadas segundo uma escala de gravidade que vai de 0 a 5, ou seja, nenhum distúrbio, distúrbio mínimo, distúrbio evidente, distúrbio sério, distúrbio muito sério ou distúrbio extremo. Para a uniformização dos critérios de avaliação, houve um treinamento prévio dos entrevistadores, e, para uma maior confiabilidade da leitura dos conteúdos dos entrevistados, as entrevistas foram sempre realizadas por dois entrevistadores.

\section{Modelo de cura versus modelo} de reabilitação psicossocial

Desde que Kraepelin definiu esquizofrenia, ou demência precoce, há uns cem anos atrás, como uma enfermidade crônica, irrecuperável, como uma condição gradualmente deteriorada, historicamente tem havido o confronto entre as expectativas de cura dirigidas aos profis- sionais em saúde mental e a sua incapacidade de curar as enfermidades mentais consideradas graves. O cotidiano das relações entre os profissionais do tratamento, os pacientes e suas famílias é freqüentemente frustrante, insatisfatório, tão minimamente colaborativo a ponto de ser a coerção o que coordena as interações.

Na convivência com a instituição psiquiátrica, clientes e famílias se encontram à espera de que a sua doença desapareça, ou que seja curada segundo os termos médicos. Todos querem continuar a levar a vida satisfatoriamente. E suas vidas não mel horam. Voltam-se contra os profissionais de saúde mental, porque o que esperam não ocorre, porque a cura está sendo sempre postergada. Por sua vez os profissionais se sentem igualmente frustrados: a cura não ocorre, a doença desafia a sua formação profissional, o irrecuperável é a negação da sua competência profissional.

O resultado é que de Pinel, Kraepelin e Freud aos nossos dias constatamos o abandono, a negligência e a deterioração. Poucos psiquiatras de fato se dispõem a tratar de pacientes crônicos. Há mais e mais pacientes descritos como resistentes ao tratamento; as famílias se desengajam deste e a sociedade se desinteressa pela sorte dos doentes mentais. Por falta de alternativas, diz-se que a psiquiatria continua a exercer o duplo mandato de cura e de controle social!

A literatura dos críticos à psiquiatria é abundante. Do século XIX até meados do século XX, o manicômio psiquiátrico foi considerado como a modalidade terapêutica mais eficaz, reconhecendo-se o seqüestro, o isolamento e as práticas coercitivas como um mal necessário. Nessa época da história ocidental, considerava-se que a vida fora do asilo era demasiadamente dura e impiedosa para aqueles com graves problemas de interação social. O asilo era literalmente um local de refúgio, embora o gesto humanitário e civilizatório de Pinel, reproduzido pelos quatro cantos do mundo ocidentalizado, tenha sempre sido contestado por pacientes (Porter, 1987).

A legitimidade de tal violência, defendida como caminho para a cura, nunca deixou de ser contestada pela filosofia, pela ciência e pelas artes. A literatura é abundante.

Demonstra-se que as categorias de classificação social, que são próprias ao senso comum, existem em razão da sociedade em geral e não por causa dos indivíduos propriamente ditos (Lemert, 1951); há a categoria proposta por Barton (1959) de neurose institucional; fazse a análise do asilo como modelo de instituição total (Goffman, 1961); Szasz (1961, 1963) 
expõe a tese de que a enfermidade mental é um mito e que a psiquiatria institucional deveria ser refutada em nome do contrato social livremente acordado; Laing (1967) argumenta que a esquizofrenia é em princípio uma experiência existencial autêntica e que a psiquiatria é incapaz de compreendê-la por meio do modelo médico; Cooper (1967) radicaliza a crítica à psiquiatria ao denunciar a violência sistemática promovida. Na literatura francesa, uma referência obrigatória é sem dúvida Foucault (1972), para quem a história da psiquiatria é um exemplar da história da razão moderna desde Descartes, uma história de violência feita em nome da razão. Na literatura italiana, o nome que primei ramente nos vem à mente é o de Franco Basaglia (1970), porque, além da sua importância como crítico teórico, há a sua obra prática de transformação do modelo assistencial. Bruxelas, por sua vez, foi sede, em 1975, da organização da Rede Alternativa à Psiquiatria em nível internacional (Elkaim, 1977).

Se comparamos a instituição psiquiátrica ideal izada nos tempos de Pinel com a instituição psiquiátrica dos dias atuais, nas chamadas sociedades pós-industriais, não faltam evidências de que a psiquiatria vem se transformando, que se desembaraça dos velhos meios de intervenção institucional e que, graças às novas tecnologias de controle social, adapta-se aos atuais desafios de legitimação (Castel, 1981).

O modelo de cura não recupera. Segundo tal modelo, a recuperação é definida em termos negativos. Sintomas e queixas devem ser eliminados. A doença deve ser curada ou removida. Os pacientes necessitam ser aliviados das suas condições e retornar para o seu estado pré-mórbido, saudável, ou, mais precisamente, ao seu estado de não-doença. Não obstante, não há qualquer consenso na comunidade científica sobre o que é a doença, o que éa causa, o que é a cura.

Segundo tal modelo, clientes, famílias, profissionais da saúde e a sociedade em geral estamos todos igualmente condenados a ter que conviver com o fenômeno dos 'crônicos', quer dizer, com os 'irrecuperáveis'. Com outras palavras, crônico é sinônimo de investimento econômico perdido, de sucessivas reinternações psiquiátricas, de vida sem perspectivas fora da instituição, de números que denunciam a ineficiência dos agentes institucionais. Crônico é sinônimo de contradição sistemática entre as expectativas de qualidade de vida e os recursos de saúde disponíveis na sociedade.

O modelo de cura é falacioso: o indivíduo não retorna ao presumido estado-meta, nem tampouco é recuperado.

\section{O modelo de reabilitação psicossocial}

O termo reabilitação psicossocial vem sendo empregado com mais e mais freqüência no campo da saúde mental, englobando uma variedade considerável de programas assistenciais. Tais programas se destinam a diferentes grupos de pessoas, sejam aqueles tradicionalmente considerados pacientes, ou aqueles que virtualmente podem ser convertidos em pacientes psiquiátricos.

Sua clientela é a proporção significativa da população psiquiátrica que consome grande parte de sua vida literalmente confinada em instituições psiquiátricas, e também outro grande número de indivíduos que experimentam repetidas hospitalizações de curta duração ou tratamentos episódicos. Há ainda aqueles que, por terem sido pacientes psiquiátricos, são portadores de um estigma que reforça a sua marginalização no seio da comunidade, bem como a crescente parcela da população da terceira idade e os conseqüentes efeitos do seu processo de envelhecimento. Finalmente, faz parte também de sua clientela o número igualmente crescente de indivíduos com distúrbios de interação social que são jovens, desempregados e sem perspectivas de trabal ho, desprotegidos do sistema de seguro social, freqüentemente com experiências com a justiça criminal e/ ou agências de tratamento de toxicômanos (Talbott, 1980; Turner \& Wan, 1993; Castillo et al., 1991; Pélicier, 1991).

Trata-se de homens e mulheres cuja complexidade existencial não se reduz a um conjunto de sintomas clínicos.

"O momento no qual a pessoa em crise vem a ser obj eto de atenção pode ser identificado como o ponto de si mplificação máxima da relação. Por um lado, o sujeito, para se manifestar, já veio simplificando progressivamentea complexidade de sua existência sofri da, reduzindo-a a um certo número de sintomas; por outro Iado, o serviço, seja qual for, se equipou, como por um efeito de espel ho, para perceber e reconhecer esses sintomas que se apresentam como modelo de simplificação ulterior" (Dell'Acqua \& Mezzina, 1991:7).

Vários autores descreveram as necessidades da clientela sob uma perspectiva distinta da sintomatologia clínica. A sua extensão vai desde as de natureza material, como comida, teto para morar, vestuário e remédios, àquelas outras psicossociais propriamente ditas, como o desenvolvimento de capacidades para lidar com o cotidiano, o conhecimento dos meios para liberar-se de relações patologicamente dependentes, o desenvolvimento da auto-estima, 
da autonomia, ou ainda necessidades de natureza jurídico-política, como direitos civis e liberdades (Glasscote, 1971; Marcos, 1983; Robatel, 1991; Munetz \& Geller, 1993; Eastman, 1994).

A Associação Internacional de Serviços de Reabilitação Psicossocial (IAPRS) identifica nove extensivas categorias de serviços: serviços vocacionais - treinamento pré-vocacional, programas de emprego transitório, cooperativas de trabalho, oficinas protegidas, programas de alocação profissional; serviços de alojamento - abrigos, centros de emergência, lares de tempo parcial, repúblicas, financiamento da casa própria, cooperativas habitacionais entre os usuários; serviços sócio-recreativos - treinar habilidades para as tarefas cotidianas, ser membro de atividades autogestionárias, participar de atividades de natureza de clube social, ou de atividades esportivas e culturais; serviços educacionais - cursos de educação fundamental, cursos de educação especial; serviços de ajustamento pessoal - gerenciamento de caso, avaliações de metas de vida, aconsel hamento pessoal, monitoramento de medicação; serviços de apoio - consulta e educação com as famílias, trabalho com as 'redes sociais' de apoio, assessoria aos grupos de auto-ajuda, acompanhamento aos clientes para se conectarem com as instituições comunitárias; serviços de contato - referência com outras agências, obtenção de transporte necessário, realização de serviços para os clientes, correspondência entre os membros; serviços de orientação para as necessidades básicas - assistência aos membros para a aquisição da al imentação necessária, roupa e abrigo, para o sustento financeiro, para a procura dos serviços de saúde, para a proteção pessoal; serviços de orientação dos direitos de cidadania - advocacia, participação no planejamento dos serviços de saúde, urbanos e comunitários em geral.

\section{Modelo de cura e a clientela do CPPII}

Se depender da leitura dos prontuários para saber o que se faz no CPPII, a impressão que se tem é que a qualidade da produção está muito aquém do esperado.

Espera-se encontrar uma descrição pormenorizada e sistemática da clientela, mas o que há são informações genéricas, dispersas, descontínuas: a clientela é desconhecida, as sucessivas hospitalizações pouco acrescentam ao conhecimento que os técnicos têm da sua clientela.

Espera-se que o trabalho das diferentes categorias profissionais seja interdisciplinar, po- rém o que um faz é desconhecido pelo outro: não há articulação entre as diferentes competências profissionais, não há uma comunidade de intenções e objetivos.

Espera-se que as relações sejam horizontais e participativas, entretanto a autoridade e o poder do médico psiquiatra são conservados na hierarquia das competências: a base da pirâmide está reservada aos pacientes e aos familiares; nos níveis intermediários, estão os paramédicos, que agem literalmente como auxiliares do psiquiatra.

Espera-se que sejam oferecidas modalidades terapêuticas de acordo com as necessidades clínicas múltiplas e diversificadas da clientela: o que majoritariamente é feito é prescrever e administrar psicofármacos.

Espera-se que o que foi investido na clientela, no período da hospitalização, tenha na recuperação psicossocial o seu critério maior de avaliação. O que se observa são sucessivas e constantes reinternações. Há ainda o problema da desestruturação do sistema de assistência na cidade, o que vem causando aumento considerável do número de pacientes provenientes de outras áreas programáticas (Aps).

\section{A clientela, a crise e a porta de entrada no sistema}

Apenas 4\% dos casos registrados são de indivíduos que procuram voluntariamente o serviço, $13 \%$ sob demanda de agentes de segurança (polícia, corpo de bombeiro), 6\% acompanhados por interessados (amigos, por exemplo) e $74 \%$, pelos familiares.

O valor de base que justifica a hospitalização do indivíduo é definido segundo o sistema de reconhecimento do Pronto-Socorro Psiquiátrico (PSP). Tal sistema funciona numa relação especular com as queixas da clientela. A transformação da 'linguagem ordinária' em discurso 'sintomatológico' pode ser feita em termos de sofrimento, de comportamento perturbador ou socialmente perigoso, de estado de miséria e de marginalidade, de crise nas relações familiares, de dificuldades no trabalho, de incompreensão de certas condutas, de intolerância ao ambiente.

"Emagrecendo muito, pouco apetite, recusa medicamentos, bebendo muita água."

"A paciente recebeu al ta do sanatório X na mesma semana, eapesar do uso de medicamentos apresenta sintomas." ção."

"Está insone e agressivo, não usa medica-

"A paciente procura o atendimento ambulatória, suja, sem comida." 
“Agressividade com familiares, brigas (espancamento)."

"Quebra objetos, recusa al imentos ehigiene, tem insônia, risos, alucinações e delírios."

"A pacientefoi internada porque os familiares a abandonaram na porta do hospital."

“Não consegue dormir, nem se alimentar, quebrou diversos objetos da casa e toma banho diversas vezes."

"Início da doença atual se deu há anos, piora há um mês, por ocasião do falecimento do marido, casados há 17 anos."

"Acompanhante alega ingestão de grande quantidade de bebida alcoólica."

"Perdeu um filho recentemente num acidente de moto, voltando a beber e usar drogas."

"Fez arruaça ecaiu do trem, uso de cocaína."

O PSP está compreendido por dois setores: a Emergência (16 leitos - quatro masculinos, quatro femininos, quatro infantis e quatro de emergência clínica) e a Enfermaria de Acolhimento da Crise (17 leitos femininos e os leitos masculinos da Unidade Hospital Professor Adauto Botelho - UHPAB).

O nome Pronto-Socorro Psiquiátrico diz o que se espera dele: intervenções imediatas sobre a crise. Na prática, a Emergência funciona sobretudo como uma agência de triagem entre os que terão o atendimento ambulatorial, os que serão internados no CPPII, e principalmente os que devem ir para uma clínica conveniada. No período de 8 de agosto a 25 de setembro de 1995, dos 698 casos, $73 \%$ foram transferidos para as clínicas conveniadas: um dado que diz muito sobre a porta de entrada do sistema.

Suas intervenções terapêuticas e seus serviços, definidos como de curta duração, não dispõem de recursos necessários. Na Emergência não resta aos pacientes senão a sua permanência nos leitos, quando não são amarrados. Não existe qualquer espaço de convivência, de reunião, ou de privacidade: o contexto é da mais absoluta permissividade. A Emergência é, na realidade, uma grande 'cela-forte'.

A entrevista do psiquiatra é realizada segundo os parâmetros da sintomatologia, a fim de determinar a especificidade, a classificação dos comportamentos e a homologação de partes de problemas.

As queixas são codificadas segundo sinais e sintomas: heteroagressão, delírio persecutório (místico, de grandeza etc.), estado de agitação, alucinações, insônia, abulia, dissociação, crítica abolida, automatismo, ansiedade, angústia, medo, embotamento afetivo, compulsão, descuido com a higiene pessoal, hipoatividade etc.

As combinação de tais sinais e sintomas são classificáveis como entidades nosológicas, construídas segundo o modelo clínico da medicina somática: há o estado-meta do organismo, do qual se desvia a enfermidade, que se espera ser conhecido por indicadores empíricoanalíticos, ou por indicadores empíricos intuitivamente interpretados. Segundo tais critérios clínicos, a clientela do CPPII está distribuída de acordo com a Tabela 1.

O verdadeiro diagnóstico, em se tratando da clínica propriamente dita, é aquele que consiste não somente em reconhecer que o paciente é afetado mais por tal enfermidade do que por aquela outra, como também em possibilitar a formulação, com uma razoável aproximação, de um prognóstico, ou melhor, de uma série de possibilidades de cura - de retorno ao estado-meta -, em virtude de fatores - variáveis - avaliáveis de caso para caso.

Em números relativos, há cerca de $31 \%$ de casos classificados no grupo de outras psicoses; $24 \%$ de esquizofrênicos; $14,4 \%$ de indivíduos com neuroses e transtornos da personalidade; 9,3\% de alcoolismo, e assim por diante. O que se espera? Que existam perspectivas diferenciadas para 1,4\% de oligofrênicos, assim como para $24 \%$ de esquizofrênicos ou para 1,0\% de dependentes de drogas. Na Emergência, não se fazem prognósticos, ou seja, estatisticamente todos estão homogeneizados segundo o critério de ausência de prognóstico - o famigerado ‘nada consta'. Talvez seja porque no PSP a situação de crise seja a mesma: todos são igualmente agrupáveis para os mesmos procedimentos terapêuticos.

Na Emergência Psiquiátrica, o procedimento terapêutico é o mesmo para todos os pacientes, com raríssimas exceções, ou seja: contenção e psicofármacos.

Retomemos a distribuição da clientela do CPPII acima apresentada. A mesma distribuição pode ser reapresentada de uma outra maneira, ou seja, como a morbidade se distribui dentro de cada categoria nosográfica.

Olhar para a Tabela 2, diferentemente distribuída, permite-nos um outro enfoque, igualmente epidemiológico. Com perguntas tais como: Por que $76,3 \%$ das psicoses afetivas ocorrem no sexo feminino? Por que o alcoolismo é majoritariamente um problema masculino? Por que, entre os casos de fatores mentais por disfunções fisiológicas, $0 \%$ é do sexo feminino? Ou ainda: O que significa que $56,7 \%$ dos casos sejam de pessoas entre 18 e 44 anos, a idade socialmente produtiva, no que se refere a trabaIho, a sexualidade, a composição familiar? Tais questões deveriam apontar programas, tanto em termos curativos (?), como aqueles esperados de prevenção e de reabilitação (afinal de 
Tabela 1

Distribuição dos diagnósticos da população do PSP do CPPII, por sexo e idade segundo grupo de causas, em 1994.

\begin{tabular}{|c|c|c|c|c|c|c|c|c|c|}
\hline \multirow[t]{2}{*}{ Grupo de causas } & \multirow[t]{2}{*}{ Total pacientes (\%) } & \multicolumn{2}{|c|}{ Sexo $(\%)$} & \multicolumn{6}{|c|}{ Faixas etárias (\%) } \\
\hline & & Masc. & Fem. & $0-11$ & $12-17$ & $18-44$ & $45-64$ & 65 e mais & Ignorado \\
\hline Psicoses senis e pré-senis & 1,4 & 1,2 & 1,6 & 0,0 & 0,4 & 0,3 & 2,1 & 17,4 & 0,6 \\
\hline Psicoses esquizofrênicas & 24,8 & 23,3 & 26,8 & 8,3 & 20,3 & 28,5 & 20,1 & 15,7 & 21,4 \\
\hline Psicoses afetivas & 5,3 & 2,3 & 9,0 & 0,0 & 2,0 & 4,4 & 8,6 & 8,5 & 3,8 \\
\hline Outras psicoses & 31,7 & 31,9 & 31,4 & 25,0 & 34,6 & 32,8 & 29,4 & 25,8 & 31,8 \\
\hline $\begin{array}{l}\text { Neuroses e transtornos } \\
\text { da personalidade }\end{array}$ & 14,4 & 11,3 & 18,3 & 12,5 & 6,5 & 12,0 & 17,1 & 19,9 & 21,3 \\
\hline Alcoolismo & 9,3 & 15,1 & 2,2 & 4,2 & 0,8 & 9,2 & 12,9 & 3,8 & 8,1 \\
\hline Dependência de drogas & 1,0 & 1,4 & 0,4 & 0,0 & 3,7 & 1,2 & 0,0 & 0,0 & 0,9 \\
\hline $\begin{array}{l}\text { Fatores mentais por } \\
\text { disfunção fisiológica }\end{array}$ & 0,0 & 0,1 & 0,0 & 0,0 & 0,0 & 0,1 & 0,1 & 0,0 & 0,0 \\
\hline Oligofrenias & 1,4 & 1,6 & 1,2 & 4,2 & 7,3 & 1,4 & 0,3 & 0,4 & 1,9 \\
\hline $\begin{array}{l}\text { O utros transtornos } \\
\text { não psicóticos }\end{array}$ & 0,7 & 0,9 & 0,4 & 0,0 & 4,1 & 0,6 & 0,6 & 0,0 & 0,0 \\
\hline Epilepsia & 5,8 & 6,4 & 5,0 & 33,3 & 13,0 & 5,7 & 4,6 & 1,7 & 6,1 \\
\hline Sem diagnóstico & 4,2 & 4,5 & 3,8 & 12,5 & 7,3 & 3,7 & 4,1 & 6,8 & 4,2 \\
\hline $\begin{array}{l}\text { Porcentagem total } \\
\text { de pacientes }\end{array}$ & 100 & 100 & 100 & 100 & 100 & 100 & 100 & 100 & 100 \\
\hline & 6.296 & 3.478 & 2.818 & 24 & 246 & 3.570 & 1.430 & 236 & 790 \\
\hline
\end{tabular}

Fonte: CPPII/Didam, 1994.

Tabela 2

Distribuição dos diagnósticos da população do PSP do CPPII, segundo grupos de causas por sexo e idade, em 1994.

\begin{tabular}{|c|c|c|c|c|c|c|c|c|c|}
\hline \multirow[t]{2}{*}{ Grupo de causas } & \multirow[t]{2}{*}{ Total pacientes } & \multicolumn{2}{|c|}{ Sexo $(\%)$} & \multicolumn{6}{|c|}{ Faixas etárias (\%) } \\
\hline & & Masc. & Fem. & $0-11$ & $12-17$ & $18-44$ & $45-64$ & 65 e mais & Ignorado \\
\hline Psicoses senis e pré-senis & 87 & 49,4 & 50,6 & 0,0 & 1,1 & 11,5 & 34,5 & 47,1 & 5,7 \\
\hline Psicoses esquizo frênicas & 1.563 & 51,8 & 48,2 & 0,1 & 3,2 & 65,1 & 18,4 & 2,4 & 10,8 \\
\hline Psicoses afetivas & 334 & 23,7 & 76,3 & 0,0 & 1,5 & 46,7 & 36,8 & 6,0 & 9,0 \\
\hline Outras psicoses & 1.995 & 55,7 & 44,3 & 0,3 & 4,3 & 58,7 & 21,1 & 3,1 & 12,6 \\
\hline $\begin{array}{l}\text { Neuroses e transtornos } \\
\text { da personalidade }\end{array}$ & 909 & 43,3 & 56,7 & 0,3 & 1,8 & 47,3 & 27,0 & 5,2 & 18,5 \\
\hline Alcoolismo & 588 & 89,3 & 10,7 & 0,2 & 0,3 & 55,8 & 31,3 & 1,5 & 10,9 \\
\hline Dependência de drogas & 60 & 81,7 & 18,3 & 0,0 & 15,0 & 73,3 & 0,0 & 0,0 & 11,7 \\
\hline $\begin{array}{l}\text { Fatores mentais por } \\
\text { disfunção fisiológica }\end{array}$ & 3 & 100 & 0,0 & 0,0 & 0,0 & 66,7 & 33,3 & 0,0 & 0,0 \\
\hline Oligofrenias & 91 & 62,6 & 37,4 & 1,1 & 19,8 & 56,0 & 5,5 & 1,1 & 16,5 \\
\hline $\begin{array}{l}\text { O utros transtornos } \\
\text { não psicóticos }\end{array}$ & 41 & 75,6 & 24,4 & 0,0 & 24,4 & 56,1 & 19,5 & 0,0 & 0,0 \\
\hline Epilepsia & 363 & 60,9 & 39,1 & 2,2 & 8,8 & 56,5 & 18,2 & 1,1 & 13,2 \\
\hline Sem diagnóstico & 262 & 59,5 & 40,5 & 1,1 & 6,9 & 50,8 & 22,5 & 6,1 & 12,6 \\
\hline Total de pacientes & 6.296 & 55,2 & 44,8 & 0,4 & 3,9 & 56,7 & 22,7 & 3,7 & 12,5 \\
\hline
\end{tabular}

Fonte: CPPII/Didam, 1994. 
contas, o CPPII éa instituição psiquiátrica pública de referência para mais de dois milhões de cidadãos do Município do Rio de Janeiro!)

A Emergência do CPPII, na realidade, não tem outra função sistêmica além de agenciar a classificação e a distribuição da clientela segundo critérios de percepção e de julgamento alheios ao que cientificamente é esperado, seja pelos técnicos, seja pelos pacientes, pelas famílias e pela sociedade em geral. É arbitrário o diagnóstico: para quem já teve uma internação prévia no CPPII, tomando como referência os prontuários, cerca de $48,3 \%$ dos diagnósticos dados em 1994 não repetem o anteriormente dado; mesmo entre pareceres do mesmo psiquiatra, cerca de $15,3 \%$ dos diagnósticos não se repetem. Feito o diagnóstico não há qualquer retorno para que o seu autor e a instituição possam avaliar o serviço que foi prestado.

$\mathrm{Na}$ realidade, o PSP não corresponde ao conceito de crise, correto do ponto de vista teórico de reconsiderar a demanda através de uma investigação sobre o ' $x$ ' da psiquiatria: 0 sofrimento existencial do sujeito, como unidade biológica, membro de um sistema, ou sujeito social. Como se acaba de demonstrar, não há qualquer metodologia que permita retraçar as origens de tal sofrimento e de seus condicionamentos.

\section{A clientela, as unidades hospitalares} e o seu destino

É importante não esquecer de alguns fatores conjunturais que são determinados por certa política de 'desospitalização', definida como redução de leitos hospitalares e do período de hospitalização, e de que tal política não é sinônimo de 'desinstitucionalização' (Freitas, 1994). No CPPII, assim como nos demais hospitais psiquiátricos públicos, há uma tendência a impedir que haja a internação de longo termo.

Se na Emergência sabe-se sobre o indivíduo apenas o que é apresentado na simplificação da sintomatologia, nada é substancialmente alterado quando o paciente está em alguma das unidades de hospitalização propriamente dita.

O paciente não tem um percurso afetivo, social e institucional reconstruído. E o insólito é que $74 \%$ da clientela que chegou ao CPPII em 1994 tenham prévias internações, e que 60,8\% dessas internações sejam no próprio CPPII. Com uma clientela tão 'fiel', seria de esperar haver tempo para as mais distintas abordagens. Procedimentos terapêuticos? Além dos psicofármacos, da hospitalização - que dá direito a um teto, à roupa, à alimentação e ao asi- lo - muito pouco do oferecido merece ser chamado de terapêutico. Grupos operativos? É a reunião de um grupo de pacientes: eficiente para ocupar o tempo ocioso. Atividades de Terapia Ocupacional? São freqüentemente papel e tinta, massa de modelar, cerâmica, linha de tricô... . Deve haver alguma razão terapêutica, ainda desconhecida pela comunidade científica, que justifique submeter adultos a um estágio no pré-escolar. E que ironia: o CPPII é reconhecido nacional e internacionalmente como o espaço de trabalho revolucionário de alguém como a Dra. Nise da Silveira!

\section{Considerações intermediárias}

O que acaba de ser apresentado e analisado pode levar a considerações equivocadas. Tal quadro de irracionalidade institucional não é privilégio do CPPII. Trata-se da irracionalidade do sistema psiquiátrico dominante no nosso país e na grande maioria dos países latinoamericanos, conforme foi apresentado na Conferência Regional da Organização Panamericana da Saúde em Caracas, em 1990. Em grandes traços, os problemas do CPPII são idênticos aos da assistência em saúde mental em geral:

- o 'hospitalocentrismo' como modelo de intervenção hegemônico;

- a falta de planificação para a atenção das populações definidas;

- o fato de os serviços não serem integrais e integrados;

- o fato de os serviços não garantirem continuidade de cuidados, limitando-se aos casos episódicos nos momentos críticos de exasperação dos problemas;

- a despersonalização da atenção, o que desfavorece qualquer adesão ativa dos implicados no tratamento;

- a ausência de dispositivos democráticos que garantam a participação da clientela e da sociedade em geral nos processos de programação, desenvolvimento e avaliação da eficiência, da eficácia e da eqüidade.

O que se passa no CPPII são efeitos iatrogênicos, digamos assim, já descritos pela comunidade científica internacional:

- o isolamento físico e psicossocial, o que favorece a violação dos direitos humanos elementares e a estigmatização do paciente, da família e da rede social implicada;

- a concentração dos esforços profissionais para administrar os hospitalizados, retirando os recursos humanos e terapêuticos necessários em outros contextos, como os hospitais gerais, os ambulatórios, os centros de cuidados 
primários, as escolas, o atendimento domiciliar etc.;

- o tratamento exclusivamente episódico e sem qualquer planificação de continuidade, reforçando a cultura hospitalar, a 'cronificação' e o fenômeno da readmissão;

- a centralização hospitalar transformada também em espaço privilegiado para o desenvolvimento das capacidades dos recursos humanos nos níveis da pré e da pós-graduação, onde a formação é limitada às formulações médicas, biométricas e administrativas, e a aprendizagem recebida é aquela segundo a qual os distúrbios mentais devem ser tratados conforme o modelo de cura e em hospitais.

O que se passa no CPPII muito provavelmente é o mesmo que se passa na Colônia Juliano Moreira, ou em qualquer hospital psiquiátrico como tal, o que merece ser mais bem investigado para melhor subsidiar o debate em torno da reforma psiquiátrica em curso.

Sintomatologia, deficiência e incapacidade

A O.M.S. propõe uma diferenciação entre a sintomatologia, as deficiências e as incapacidades.

“O concei to de enfermi dade se refere geralmentea um estado ou a um processo percebi do como desviante com respei to ao estado de saúde normal (estado de sofrimento ou estado inquietante) implicando uma lesão ou um disfuncionamento fisiológico (demonstrado ou presumido), e podendo ser descrito em termos de sintomas. De acordo com a classificação internacional das deficiências, incapaci dades e desvantagens, uma deficiência correspondea 'toda perda ou alteração de uma estrutura ou de uma função psi cológica, fisiológica ou anatômica'. Uma deficiência determinada pode ser um sintoma numa enfermidade, porém ela indica sempre mais uma perturbação funcional do que um diagnóstico nosográfico específico. Por exemplo, um déficit cognitivo corresponde precisamente a uma defici ência sem por isso ser uma enfermidadeespecífica. A incapacidade se define como ‘uma redução (resul tante de uma deficiência) parcial ou total da capacidade de realizar uma atividadesegundo uma maneira ou nos limi tes considerados como normais para um ser humano'". (OMS/ DAS, 1989:79-80)

\section{Capacidade interativa e o contexto} de vida

O conceito de capacidade interativa surge da necessidade de se considerar a existência de qualificações básicas inerentes à partici pação dos indivíduos em sistemas de interação, à solução de problemas interpessoais e à aprendizagem.

Tal conceito é complementar ao conceito de mundo-da-vida, de origem eminentemente fenomenológica, que afirma que as nossas interações reais e possíveis são indissociáveis do fato de que esse mundo compartilhado intersubjetivamente seja inseparável de nosso corpo, de nossa linguagem e de nossa história social.

Esta complementaridade deve ser entendida de acordo com os seguintes termos:

- Este mundo aqui-e-agora é intersubjetivamente compartilhado por atores possuidores de capacidades interativas com o seu mundo interior, a natureza externa, o mundo social e a linguagem.

- As capacidades interativas são adquiridas pelo estabelecimento e o desenvolvimento progressivo de relações objetais, cuja racionalidade aumenta na medida da diferenciação do mundo.

- Entende-se por natureza externa os estados de coisas que são objeto de intervenções cognitivo-instrumentais (a natureza inanimada e o conjunto dos objetos da experiência objetivante); por mundo social, os fragmentos da realidade simbolicamente pré-estruturada que o sujeito pode compreender numa atitude não objetivante, quer dizer, como participante de um sistema de comunicação (emissões e ações, instituições, tradições, valores culturais, objetivações dotadas de conteúdo semântico, os sujeitos como atores sociais); por mundo interior, a natureza desejante e os referenciais de identidade (são as estruturas internas, necessidades e controles) e, finalmente, por linguagem entende-se o meio das nossas emissões e manifestações.

- A individuação é formada como um sistema de interseções múltiplas entre as estruturas internas e as estruturas externas, realizadas evolutivamente em termos de aprendizagem (diferenciação e adaptação) e de síntese.

- A individuação se procede pela socialização graças às interações coordenadas pela linguagem, porque, por um lado, a linguagem é o meio de transferência, ao sistema de personalidade, de uma configuração determinada de estruturas do mundo-da-vida próprio ao seu meio familiar e, por outro lado, ela se apresen- 
ta como maneira de organizar os desejos susceptíveis de interpretação.

- As perturbações interativas podem ser analisadas em dois planos: no plano dos quadros patogênicos do ambiente relevantes para a socialização e no das necessidades e controles de comportamento formados nas condições de uma "comuni cação sistematicamente deformada" (Habermas, 1989:193-229).

Graças ao interacionismo simbólico desenvolvido a partir da obra de Mead (1934), sabemos que o self, enquanto capacidade reflexiva de ser igualmente sujeito/ objeto, emerge e se desenvolve no processo das interações sociais mediadas pela linguagem - especialmente pelas capacidades do 'agir comunicativo'. Em outras palavras, o indivíduo não experiencia a si mesmo diretamente, mas indiretamente: valendo-se das perspectivas (standpoints) dos membros do seu grupo social imediato, ou da perspectiva do 'outro generalizado' (generalized other). Pela linguagem, o indivíduo interpela e responde a si mesmo, fala a si próprio e se autocontesta, da mesma forma como os outros falam a ele e o contestam, assumindo papéis reversíveis, intercambiados, atitudes complementares como as requeridas num jogo (play, gamee generalized other). O processo de individualização realiza-se em concomitância com o processo de assunção de diferentes relações com diferentes pessoas. Somos um com um outro, somos outra pessoa com um outro indivíduo: somos uma pluralidade de outros. $\mathrm{E}$ somos também o mesmo, na relação do nosso self consigo mesmo. Conseqüentemente, dividimos o nosso self em todas as espécies de selves, com referência às nossas experiências pessoais: somos uma unidade de múltiplos selves, respondendo a todo tipo de diferentes reações sociais, as atitudes dos outros a meu respeito constituindo o 'de mim para o outro' e o modo como reajo constituindo o eu (a diferença entre mee I). “Uma personalidademúltipla énum certo senti do normal" (Mead, 1934). Somos muito mais possi bilidades daquilo que é realizado em cada situação, pois cada contexto reativa sentido, normas e papéis sociais do transfundo comum, constituído pelas estruturas do chamado mundo-da-vida. É inerente à intersubjetividade a reativação de partes do self em cada contexto: neste momento em que escrevo este texto, sou escritor em relação aos leitores, sou o que eles esperam que eu Ihes diga, o que já sabem sobre o assunto, se o modo como estou apresentando o problema é reconhecível, o que espero que os leitores respondam etc., não sendo pertinente a este aqui-e-agora a minha idade, meu estado civil, se faço esportes, se sou místico e assim por diante, embora em outros contextos tais partes do meu self possam ser ativadas. Contudo, é igualmente inerente à intersubjetividade que partes do self se tornem definitivamente impossíveis de ser compatibilizadas, integradas, graças a fatores patológicos presentes: são lembranças dolorosas que não caem no esquecimento e, com elas, partes do self que se quer deixar para trás, por serem percebidas como aprisionamento a um passado determinado, ou por uma comunicação sistematicamente distorcida, a requerer o desempenho de papéis mesmo quando se negam entre si a produzir uma clivagem do comportamento.

O pensamento de Mead encontra ressonâncias nos diversos campos do saber contemporâneo. Nas ciências cognitivas: os conceitos de auto-organização e o de fazer-emergir sobre um transfundo (Varela, 1989). Na sociologia: o conceito de agir dramatúrgico (Goffman, 1973). $\mathrm{Na}$ filosofia da linguagem: os conceitos de esquemas e de modelos mentais (Devitt $\&$ Sterenly, 1995). Na sócio-lingüística: o conceito de convenções de contextualização (Gumperz, 1989). O conceito de double bind, desenvolvido pela Escola de Palo Alto, tendo por base a formulação inicial de Bateson (Wittezaele \& Garcia, 1992). O conceito habermasiano de "comunicação sistematicamente deformada" (Habermas, 1989). Ou, finalmente, o pensamento filosófico sobre o ‘mesmo' e o 'outro' e as suas implicações éticas (Ricoeur, 1990).

\section{Capacidades interativas e reabilitação} psicossocial em psiquiatria

Tradicionalmente a medicina tem equacionado recuperação com cura. Porém, até a presente data, não se pode falar de cura de doenças mentais sérias (Spaniol, 1994). Por isso é que a tendência atual é enfatizar a recuperação em termos de reabilitação psicossocial ou readaptação.

“O que envolvea reorganização éa aceitação do self detal maneira a haver sentido e propósito de vida que transcenda a doença mental. Assume-sequenão há um ponto final que possa ser al cançado agora e para sempre. Mas sim que há um processo no qual os indivíduos trabaIham continuamente para maximizar a satisfação das suas necessi dades, mesmo quando uma séria desordem no cérebro exige um formidável desafio de adaptação." (Hatfield, 1990:6)

Estar no mundo como doente mental implica ser diferente das expectativas: querer retornar a uma realidade conhecida antes de es- 
tar doente e não conseguir; reconhecer-se como limitado para além dos limites enfrentados pela maioria das pessoas; ter comprometidos os objetivos de vida; não ter esperanças de que a sua vida possa ser melhor; saber que a totalidade do seu ser social está definida pela doença mental.

Estar no mundo como doente mental é o mesmo que ter perdido a autodeterminação: a volição, o autocontrole, o poder de querer parece ter desaparecido; a vida se reduz aos sintomas que o transformam em paciente de algo incontrolável: forças demoníacas, causas orgânicas, ausência de 'fibra moral', má família, Édipo mal-resolvido, e assim por diante.

Estar no mundo como doente mental é estar limitado a ser subordinado ao papel de doente mental: é impossível ser reconhecido como pai, mãe, filho, solteiro, divorciado, empregado ou desempregado, intelectual, lavrador, escriturário, operário, nordestino ou carioca, jovem ou idoso, branco ou negro; é ter que estar submetido às barreiras do estereótipo doente: alguém que não pode estar empregado, constituir família, assinar um documento, responder pelos seus atos.

Os programas de reabilitação psicossocial desenvolvidos como al ternativa ao modelo de cura têm em comum a seguinte estratégia metodológica (Freitas, 1994):

- pôr entre parênteses a doença mental e assim proceder a uma 'elucidação hermenêutica' dos quadros de referência que orientam o reconhecimento/denominação dos elementos de vida problematizados pela crise interativa; - a desmontagem e a reconstrução dos contextos interativos patológicos, visando à desinstitucionalização;

- o desenvolvimento das capacidades dos agentes sociais nos contextos de tempo e de espaço cambiantes;

- a reativação de redes sociais de solidariedade e de justiça disponíveis (comunidade, setor, território).

\section{A clientela do CPPII e os indicadores da reabilitação psicossocial}

A aplicação da escala OMS/ DAS aborda as capacidades interativas abaixo segundo os seguintes aspectos:

- aspecto e aparência pessoal: designa as atividades e os tipos de comportamento exigidos para a manutenção do equilíbrio e da sobrevivência fisiológicos (alimentação, excreção, higiene pessoal, evitação de um perigo físico), a apresentação pessoal em sociedade (vestuário, cuidados), bem como as atividades e comportamentos executados normalmente pelos adultos não deficientes, que demandam um mínimo de assistência de outras pessoas.

- atividades: relaciona-se ao ritmo e à qualidade de execução, compreendendo a realização de ações e a participação em eventos prescritos por um conjunto de codificações e de crenças de um grupo social; a atividade pode ser formal, como, por exemplo, em um clube, em uma organização beneficente, em um partido político, ou informal, como manter um círculo de amigos, relações familiares ou de vizinhança.

- isolamento social: indica um modo de comportamento caracterizado por uma tendência persistente de se retrair da interação e da comunicação sociais. As convenções sociais reconhecem certas motivações, circunstâncias e papéis sociais, que fazem do retorno sobre si mesmo um fenômeno admitido, não conduzindo a um disfuncionamento psicossocial. Em caso contrário, o isolamento social é geralmente considerado como um desvio, indicando a presença de um distúrbio mental ou traços de personalidade subnormais.

- papel na família: designa os papéis sociais respectivos, próprios da vida em família. Cada um desses papéis compreende um componente de atenção (solicitude e proteção) e de afeição, e cada um deles se funda estreitamente no papel de pai, de mãe e de filho.

- relações sexuais: no contexto do DAS, designa os papéis sexuais manifestados pelo interesse por uma pessoa do sexo oposto, a busca de uma relação de intimidade física heterossexual, matrimonial ou extramatrimonial.

- papel profissional: termo genérico atribuído a uma grande variedade de papéis sociais ao redor de centros de interesses comuns. Os papéis profissionais são geralmente definidos por tarefas e obrigações específicas, conhecimentos e competências necessárias, níveis de execução e de rendimento. Com a realização de um papel profissional, normalmente se espera a produção de bens materiais, de serviços ou outros (incluído o setor intelectual e artístico), que proporcione alguma recompensa.

- centros de interesse: designa interesses em atividades sócio-recreativas, educacionais, leituras, lazer, religião etc.

- situações de urgência ou circunstâncias imprevisíveis: designa como o indivíduo reage em situações fora da rotina, que exigem uma ação imediata, uma solução e uma iniciativa, segundo as expectativas de confiabilidade, credibilidade e sentido de responsabilidade.

As questões formuladas aos entrevistados são feitas em razão de expectativas, quer dizer, 
da antecipação comum aos membros de um grupo, segundo a qual um comportamento individual em diferentes situações é previsível em certos limites e se conformará aos modelos ou estereótipos de referência. O conceito de expectativas está relacionado ao de norma social. Por norma social entende-se, no contexto do DAS, o conjunto dos modos de comportamentos sociais e de realização dos papéis sociais esperados pelo consenso social de um grupo ou de uma cultura de referência precisa. Na medida em que o consenso social reflete geralmente um acordo grupal implícito e informal, a maioria das normas sociais corresponde a um nível tipo ou a um nível médio de realização de papéis específicos desse grupo.

A avaliação das competências é codificada de 0 a 5, respectivamente: nenhum distúrbio, distúrbio mínimo, distúrbio evidente, distúrbio sério, distúrbio muito sério e distúrbio máximo.

Idade: Dos 21 casos, dois indivíduos (9,5\%) têm menos de 18 anos; 17 (81\%) estão entre os 21 e os 52 anos, e, finalmente, estão na chamada terceira idade os dois indivíduos (9,5\%) com idade acima de sessenta anos. Isto significa que a esmagadora maioria é constituída por indivíduos em plena idade produtiva, e que a população da terceira idade ainda é muito pequena, em comparação com a situação das chamadas sociedades pós-industriais.

Situações imprevisíveis/ de urgência: É onde se concentram com mais intensidade as queixas referenciadas pelos escores que apontam a presença de distúrbios comprometedores para a interação, pois totalizam 14,3\% os casos avaliados como distúrbio sério; $23,8 \%$, como distúrbio muito sério; $19,0 \%$, como distúrbio extremo.

Centros de interesse: Dezoito indivíduos apresentam algum grau de disfuncionamento, o que significa que $85,7 \%$ da população investigada perdeu o interesse pelos acontecimentos que se passam ao seu redor, não apresenta desejo de se manter informada, tem o seu horizonte de vida limitado.

Participação na vida familiar: Tratando-se do indivíduo enquanto pai/mãe, filho(a), irmão(a), enfim, do self e daqueles papéis esperados para a reprodução da família, apenas um dos 21 indivíduos não apresenta qualquer problema; 18 (86,5\%) apresentam algum disfuncionamento, e nas categorias distúrbio sério e distúrbio muito sério há 12 indivíduos (57\%).

Papel de cônjuge: Quinze indivíduos não estão casados, incluídos os quatro casos menores de 18 e maiores de sessenta anos de idade. Dos seis indivíduos casados, apenas um não apresenta disfuncionamento do seu papel de pai/ mãe. Se levarmos em consideração as relações conjugais em termos afetivos, apenas dois casos dos seis são considerados normais. Por outro lado, ao se levar em conta a sexualidade nas relações conjugais, os mesmos dois casos anteriores são considerados sem distúrbio, ao passo que para três casos não se obteve informação, sendo difícil distinguir as dificuldades dos entrevistadores e dos entrevistados para abordar a temática da sexualidade.

Sexualidade: Trata-se da sexualidade dos que não têm uma vida conjugal. Se não consideramos os dois menores de 18 anos, 12 casos (ou 57,5\%) apresentam distúrbios na sua sexualidade. Os 33\% restantes (sete casos) estão na categoria 'sem informação'; não podemos afirmar, por conseguinte, se são indivíduos que apresentam ou não alguma disfunção no seu papel social de sexualidade.

Atividade profissional: Dos 21 casos, 17 $(81,5 \%)$ não têm uma atividade profissional, seja como trabalhador, seja como estudante.

Comportamento geral: Incluindo-se hipoatividade, esquizoidia e aspecto e higiene individuais, 17 (81\%) dos indivíduos apresentam algum grau de hipoatividade e de comportamento esquizóide; as diferenças entre os dois grupos de papel comprometido são insignificantes; sob o ponto de vista das capacidades do indivíduo para manter a sua higiene pessoal e a saúde física, de se alimentar, de conservar o seu espaço vital, seis (28,6\%) dos 21 indivíduos não apresentam qualquer comprometimento; oito $(38,1 \%)$ apresentam distúrbio mínimo, e a média entre os 21 casos agrupados neste item é a menor de todos os restantes grupos de caso, ou seja, 1,62\%, número estatisticamente significativo, se considerarmos que a média dos demais casos está acima de $2 \%$.

A distribuição por tipos e número de papéis sociais considerados como perturbados é um fator importante para programas de reabilitação psicossocial. Os dados da Tabela 3 mostram uma tendência de agravamento da disfunção do papel, significando que alguns papéis têm mais chance de ser afetados antes que os outros.

\section{Considerações finais}

A pesquisa chama a nossa atenção para algumas questões da mais absoluta importância para a reforma psiquiátrica no País. Uma delas diz respeito ao quadro de referência com o qual a maioria dos profissionais em saúde mental aprende a agir: o modelo da medicina 
Número de enfermos que apresentam disfunções do papel social em algum dos oito papéis reportados, por tipo de papel social.

\begin{tabular}{|c|c|c|c|c|c|c|c|c|c|}
\hline & $\begin{array}{l}\text { № de } \\
\text { enfermos }\end{array}$ & Profissional & $\begin{array}{l}\text { Participação } \\
\text { na família }\end{array}$ & $\begin{array}{l}\text { Centros de } \\
\text { interesse }\end{array}$ & Sexualidade & Esquizoidia & Hipoatividade & $\begin{array}{l}\text { Situação } \\
\text { imprev./ } \\
\text { urgente }\end{array}$ & $\begin{array}{l}\text { Aspecto/ } \\
\text { Higiene }\end{array}$ \\
\hline \multicolumn{10}{|c|}{$\begin{array}{l}\text { № de papéis com } \\
\text { disfuncionamento }\end{array}$} \\
\hline 4 & 1 & 1 & 1 & 1 & 0 & 0 & 1 & 0 & 0 \\
\hline 5 & 2 & 2 & 2 & 2 & 2 & 0 & 0 & 0 & 2 \\
\hline 6 & 3 & 3 & 3 & 3 & 3 & 2 & 1 & 2 & 1 \\
\hline 7 & 8 & 8 & 7 & 7 & 6 & 8 & 8 & 7 & 5 \\
\hline 8 & 7 & 7 & 7 & 7 & 7 & 7 & 7 & 7 & 7 \\
\hline $\begin{array}{l}\text { № total } \\
\text { de enfermos }\end{array}$ & 21 & 21 & 20 & 20 & 18 & 17 & 17 & 16 & 15 \\
\hline Porcentagem & 100 & 100 & 95 & 95 & 86 & 81 & 81 & 76 & 71 \\
\hline
\end{tabular}

Fonte: Dados próprios da aplicação da escala OMS/DAS.

mental. O diagnóstico e o prognóstico, o planejamento e a avaliação das prestações de serviço são procedimentos orientados por indicadores da pretensão de cura. Na medida em que a assistência é deslocada do hospital psiquiátrico para a rede de serviços comunitários destinados a trabalhar com as capacidades interativas da clientela, indicadores de natureza da reabilitação psicossocial são exigidos. Quando o hospital psiquiátrico deixar de representar a norma para o chamado circuito psiquiátrico, como serão definidos os novos sistemas de referência? Serão serviços especializados, burocraticamente diferenciados em serviços de crise, de reabilitação e de ressocialização, segundo modelos operativos mais complexos, retraçando o novo percurso terapêutico em passagens indefinidas? Na impossibilidade de definir de modo unívoco a crise e a cura, quais serão os novos valores de base para a racionalidade das prestações de serviço? Que instrumentos e quais os recursos necessários para afrontar os desafios de recuperação da relação entre o valor de saúde, o valor de vida e a crise enquanto tal? Trata-se, portanto, de componentes de um novo paradigma ainda ausente nos nossos meios acadêmico e profissional.

A outra questão não menos importante é o desrespeito com a clientela como cidadã. O cliente psiquiátrico é paciente, não é cidadão. A assistência não é prestada segundo um contrato com a clientela, onde estejam acordados objetivos individualizados segundo as especificidades da demanda e apropriados procedimentos que garantam, na sua rede social, momentos de tutela, proteção e sustentação. Essa nossa tradição é reforçada pela falta de democratização das informações. Se os dados que constam dos prontuários nem mesmo costumam ser lidos pel os companheiros de equipe, o que dizer do acesso da clientela e da população em geral ao que está sendo feito pela instituição, no cotidiano das suas prestações de serviço? O exemplo do CPPII é el oqüente. Como justificar para a sociedade a necessidade de investimento público de recursos financeiros, humanos e tecnológicos? Será que o nosso sistema assistencial resiste ao olhar do público para as suas entranhas? A situação preponderante nas nossas instituições psiquiátricas permite que a ideologia dominante, ao orientar a reforma, seja a de contenção dos gastos públicos para o setor saúde, por meio de medidas de natureza neoliberal que reduzam a reforma à racionalidade econômico-administrativa. 


\section{Referências}

BARTON, R., 1959. Institutional Neurosis. Bristol: John Wright and Sons.

BASAGLIA, F., 1970. L'Institution en Négation. Rapport sur I'Hôpital Psychiatrique de Gorizia. Paris: Seuil.

CASTILLO, F.; TELLIER, O.; VIGNES, M. \& KEBIR, AK., 1991. L'hospitalisation de la personne âgée en psychiatrie: première rencontre de la famille et des thérapeutes. In: Psychiatrie Sociale à I'Heure Européenne (P. F. Chanoit \&J. deVerbizier, orgs.), pp. 101-107, Toulouse: Erès.

CASTEL, R., 1981. La Gestion des Risques. Paris: Minuit.

CPPII - DIDAM (Centro Psiquiátrico Pedro II/Divisão de Documentação de Auditoria Médica), 1994. Arquivo do CPPII. Rio de Janeiro: CPPII. (mimeo.)

COOPER, D., 1967. Psychiatry and Anti-Psychiatry. Londres: Tavistock.

DELL'ACQUA, G. \& MEZZINA, R., 1991. Réponse à la crise, stratégies et intentions de l'intervention dans le service psychiatrique territorial. Perspectives, 18:7.

DEVITT, M. \& STERELNY, K., 1995. Language and Reality, an Introduction to the Philosophy of Language. Cambridge: The MIT Press.

EASTM AN, N., 1994. Mental health law: civil liberties and the principle of reciprocity. British Mental Journal, 308:43-45.

ELKAIM, M., 1977. Présentation. In: Réseau-Alternative à la Psychiatrie (M. Elkaim, org.), pp. 5-12, Paris: Union Générale d'Editions.

FOUCAULT, M., 1972. Histoire dela Folieà l'ÂgeClassique. Paris: Gallimard.

FREITAS, F., 1994. Vers une Psychiatrie Post-Asilaire. Propositions en Vue de Fonder un Modèle de Désinstitutionnalisation. Tese de Doutorado, Louvain-la-Neuve: Faculté de Psychologie et Sciences de l'Education, Université Catholique de Louvain.

GLASSCOTE, R., 1971. Rehabilitating the Mentally III in the Community. Washington DC: Joint Information Service of the American Psychiatric Association and the National Association for Mental Health.

GOFFMAN, E., 1961. Asylums. New York: Anchor Books, Doubleday.

GOFFM AN, E., 1973. La Mise en Scène dela Vie Quotidienne, t. 1, la Présentation de Soi. Paris: Minuit.

GU M PERZ, J., 1989. Engager la Conversation. Paris: Minuit.

HABERM AS, J., 1987. Logique des Sciences Sociales et Autres Essais. Paris: Rochlitz.
HABERMAS, J., 1989. Teoría dela Acción Comunicativa: Complementos y Estudios Previos. Madrid: Redondo, Cátedra.

HATFIELD, A. B., 1990. Recovery from mental illness. The Journal of the California Alliancefor the Mentally III, 5:6-7.

LAING, R., 1967. Politics of Experience and the Bird of Paradise. London: Penguin.

LEMERT, E., 1951. Social Pathology. New York: McGraw-Hill.

MARCOS, S., 1983. Manicomios y Prisiones, Aportaciones Críticas del I Encuentro Latinoamericano y V Internacional de Alternativas a la Psiquiatría, Realizado en la Ciudad de Cuernavaca del 2 al 6 deOctubre de 1981. México: Red-ediciones.

MEAD, G. H., 1934. Mind, Self and Society, from the Standpoint of a Social Behaviorist. Chicago: The University of Chicago Press.

MUNETZ, M. \& GELLER, J., 1993. The least restrictive alternative in the postinstitutional era. Hospital and Community Psychiatry, 44:967-973.

OMS/DAS (Organisation Mondiale de la Santé/ Echelle d'Evaluation des Incapacités Psychiatriques), 1989. Escala para a Avaliação de uma Incapacidade Psiquiátrica. Genève: OMS.

PÉLICIER, Y., 1991. Les toxicomanes aujourd'hui. In: Psychiatrie Sociale à I'Heure Européenne (P. F. Chanoit \& J. de Verbizier, orgs.), pp.345-355, Toulouse: Erès.

PORTER, R., 1987. A Social History of Madness. Londres: Weidenfeld and Nicolson.

RICOEUR, P., 1990. Soi-MêmeComme un Autre. Paris: Seuil.

ROBATEL, N., 1991. LeCitoyen Fou. Paris: P. U. F.

SPANIOL, L., 1994. The Recovery Workbook. Boston: Boston University.

SZASZ, T., 1961. The Mith of Mental IIness: Foundation of a Theory of Personal Conduct. New York: Dell.

SZASZ, T., 1963. Law, Liberty and Psychiatry: An Inquiry into the Social Uses of Mental Health Practice. New York: Macmillan.

TALBOTT, J. A., 1980. Toward a public policy on the chronically mentally ill patient. American Journal Orthopsychiatry, 50:43-53.

TURNER, J. T. \& WAN, Th. T. H.; 1993. Recidivism and mental illness: the role of the communities. Community Mental Health Journal, 29:3-14.

VARELA, F. J., 1989. Connaitre. Les Sciences Cognitives, Tendances et Perspectives. Paris: Seuil.

WITTEZAELE, J. J. \& GARCIA, T. A., 1992. La Recherche del'Ecole de Palo Alto. Paris: Seuil. 